\title{
Should Consumers Request Cost Transparency?
}

\author{
Antonis C. Simintiras, Yogesh K. Dwivedi, Geetanjali Kaushik and Nripendra P. Rana \\ School of Management, Swansea University Bay Campus, Swansea, UK
}

\begin{abstract}
Purpose - Consumers en masse lack the information to judge price fairness thereby causing their ability to influence the economy to be overlooked. In this article, we propose that consumer choice be guided by price fairness judgements to increase consumer satisfaction and subsequently enhance market efficiency.

Design/methodology/approach - This is an argumentative and conceptual work that aims to initiate a debate on this important yet unexplored issue. The arguments presented in the paper are based on economic and technological considerations.

Findings - The measure for enabling a consumer price fairness judgement is unit cost information - the cost incurred by a firm to produce a product and/or service. The benefits and challenges stemming from the availability of unit cost information (i.e. cost transparency) to consumers and companies are presented and the likely impact of cost transparency on addressing information asymmetries between buyers and sellers are discussed.

Originality/value: Although a significant body of knowledge exists on issues such as price transparency and how it is driven and enabled by the growth of the Internet, there is little or no evidence of research yet on issues related to cost transparency. We believe this work would create a new line of research for scholarly community leading to an impact on practice.
\end{abstract}

Keywords: Consumer, Cost Transparency, Information Asymmetries, Unit Cost Information, Consumer Empowerment

Paper Type Target article 


\section{Introduction}

In 2012/13, according to World Bank Group (2004), household consumption expenditure as a percentage of GDP varied from 34\% in China, 55\% in Australia, 56\% in Canada, 57\% in both France and Germany, $62 \%$ in India, $66 \%$ in the UK and $69 \%$ in the USA. ${ }^{1}$ Consumption expenditures are typically made by considering products and services that are 'best for consumers' without deliberation for what might be 'best for the overall market economy'. Personal gratification is the main and often the only driver of consumer choice. That is, as far as the chosen products and/or services meet consumers' needs and provide an expected level of satisfaction, they are content and condition their future behaviour according to those reflections. What the impact of their choice behaviour on the overall market economy and their long term interests is not usually a concern.

In a free market economy, manufacturers and providers of similar goods and services respectively that are in direct competition with each other often operate at different levels of efficiency. From an economic perspective, more efficient companies are to be preferred to less efficient companies in a market economy. Operational efficiency is the capability of a business to deliver products or services to its customers in the most cost-effective manner possible while still ensuring the high quality of its products, service and support. For instance, if two companies compete with similar products, with the efficiency level in one company being higher than the other, all else being equal, consumer choice of the product manufactured by the most efficient company is also to be preferred. Informed choices at this level presuppose that consumers have easily obtainable and relevant information required for assessing seemingly equally attractive alternatives; however, this is not the case. Consumers just see products and prices.

Accountability of achieved efficiency levels rests solely with companies. Economic theory postulates that market forces (i.e. primarily competitors) apply pressure on inefficient companies to improve or go out of business. For consumer spending (what the very existence of firms depends on) efficiency is a factor to which consumers have no input. The magnitude of household expenditures and the importance of how disposable incomes are used would logically imply that consumers ought to have information on the efficiency levels of companies. This would allow them to decide whether or not to support, through their choices, efficiently-run firms. As this information is not readily available to the consumer, companies - regardless of their efficiency - achieve market success through product/service differentiation and communications (Redmond, 2000; Rezabakhsh et al., 2006).

Product and service-related information is widely available and, although it is crucially important for buying decision-making, it is not sufficient as it does not permit judgements pertaining to the price fairness of products and services. To determine price fairness of any offering necessitates information of unit cost information. Availability of unit cost information allows the comparison of unit cost and price on any offering in addition to comparisons between alternatives; the latter would help consumers identify the best alternative in the market within the context of price 'fairness'. Making unit cost information readily available would $(a)$ enable consumers to judge the price fairness of each offering and identify the best (monetary) deal, and (b) make companies more sensitive to both cost and pricing. For example, a company charging a higher price for a comparable product with a similar unit cost will either have higher profit margins or compensate for lower levels of efficiency (i.e. the higher price tag may result from higher non-manufacturing costs).

Choice behaviour is dependent on product/service information. To make a choice, consumers' need, at least, information about the price and quality of various alternatives they

\footnotetext{
${ }^{1}$ http//:data.worldbank.org/indicator/ NE.CON.PETC.ZS
} 
consider buying. When consumers are unable to accurately ascertain the quality and value of offerings (i.e. not able to decide price fairness) malpractices/misconduct of companies cannot be foretold or predicted (i.e. companies charging high prices for low quality products). Cost transparency is therefore necessary to eradicate such problems and help consumers optimise their choice behaviour in market exchanges. Specifically, cost transparency would (a) increase consumer satisfaction with their choices (i.e. allow a-priori judgements on price fairness) and (b) provide them with the opportunity to buy from efficiently-run companies propelling, in that way, competition between companies at the level of efficiency of operations; these are necessary conditions for a more streamlined market economy.

In this article, by utilising an argumentative and conceptual approach, we postulate that cost transparency would (a) wipe out information asymmetries in the market-place, (b) empower consumers, (c) lead to better utilisation of company resources and (d) improve market efficiency. This article revolves around an assumption that price fairness judgements, facilitated by cost transparency, will benefit consumers, companies and the economy by enabling utility and efficiency maximisation of the resources available.

The remaining sections of this article are structured as follows. Section 2 reviews the relationship between availability of market information and market, price, and cost transparency through the escalation of widespread Internet for both producers and consumers. Subsequently, Section 3 discusses the concept of market transparency and its different types. The next section (i.e. Section 4) then converses about the price transparency and consumers' judgement about the offerings of products and services made available by producers. Section 5 discusses the various types of costs, one that could be most useful for the consumers, and cost transparency of products for consumers. The next section (i.e. Section 6) then discusses the benefits accruing from the availability of cost transparency for both consumers and companies. Section 7 presents the consumer empowerment and market efficiency in the context of cost transparency. The following section (i.e. Section 8) discusses how economic systems might best be served by consumers provided with the opportunity to support efficiently-run companies while pursuing their own self-interests. Finally, the paper concludes by outlining core arguments on cost transparency presented in this work.

\section{Availability of market information}

The recent escalation of widespread Internet availability has enabled an unprecedented upsurge in market information access. For example, the Internet provides consumers with information concerning available products/services, their prices and other important attributes. Moreover, the Internet allows consumers to compare prices of a single product/service offered at different retailers (e.g. mysupermarket.co.uk). Besides product attributes and price comparisons, consumers can access reviews pertaining to post-purchase evaluations and experiences of other customers (e.g. epinions.com). Even proprietary information can be obtained at some sites (e.g. travelocity.com) as consumers are granted access to the same reservation databases for flights to those used by travel agents.

The Internet dissolves the traditional distinction of information sender and information receiver as each party acts both as sender and receiver of information (Hoffman and Novak, 1997). Any Internet user can become a 'communication partner'. The removal of geographical barriers further enables the formation of online communities or networks based around common interests instead of physical proximity. Such online networks allow customers to exercise their countervailing power (Rha and Widdows, 2002). Moreover, the interactivity afforded by the Internet allows consumers to be more active within the value chain. This implies that consumer scope of activity is not bound to options of either accept or decline an offer; instead, the user can independently influence the information flow (Rha et al., 2002). 
Information on the Internet, however, is not always immune from abuse. Companies often resort to self-promoter's strategy whilst maligning the products of their competitors. In addition, firms frequently resort to counter strategies for undermining the potential empowerment of consumers by means of the Internet. Such strategies comprise of price discrimination (Ancarani, 2002; Baye and Morgan, 2002), and product differentiation and bundling (Ancarani, 2002; Ellison and Ellison, 2009). Furthermore, the anonymous nature of the web poses a threat concerning the authenticity of information - something quite difficult to validate (Hansen et al., 2006; Rezabakhsh et al., 2006). In general, and regardless of potential abuses, the Internet has increased both the quantity and quality of available information that is needed for decision-making in purchasing situations (Hansen et al., 2006; Sinha, 2000).

The marketing discourse clearly indicates a shift in power between consumers and producers. It has been concluded that over the last decade the Internet has caused a significant shift in power equations in favour of the consumer. This phenomenon is known as 'new consumer sovereignty' (Shipman, 2001) and has been recognised by various other authors (such as Carton, 2000; Rezabakhsh et al., 2006; Urban, 2002; Van Raaij, 1998). Therefore, from the signs emerging from published literature, it is evident that the role of consumers is changing. Various terms such as prosumer, consum-actor, protagonist and post-consumer have been coined to highlight the new 'roles' of the consumer. These terms are used to describe active and participative consumers along with their market experiences and relationships with firms (Cova and Dalli, 2009).

Increased levels of available information reduce information asymmetries by the elimination of the relationship between richness and reach of information (Evans and Wurster, 2000). However, as far as information richness is concerned, there exists a fundamental divide between what information is available (i.e. information offered by businesses) and what information should be available (i.e. information needed by consumers). On the one hand, firms provide information about their products/services to help consumers decide their best alternative. Consumers, on the other hand, require additional information for deciding what a fair deal is. Unless a judgement (i.e. a comparison of a price with a pertinent standard, reference, or norm) pertaining to whether or not a price of an offering is fair (i.e. price that is reasonable, acceptable, or just) (e.g. Bolton et al., 2003; Kung et al., 2002; Xia et al., 2004), judgements on what is the best deal are not possible.

Theoretically, consumers search for the best offerings from a pool of reasonable and fair alternatives. Unless all alternatives are fair and reasonable, there is a risk of sub-optimal choice behaviour. When information that is required for consumer decision-making (Murphy, 2000) is inadequate, choice behaviour is impaired (Redmond, 2000). In addition, when consumers are inadequately informed, firms can benefit by imposing their own economic interests (e.g. higher prices, reduced quality) at the cost of the consumers' interests (e.g. low prices, higher quality). This raises the question of how much consumers benefit from increased product information that does not allow them to decide what are the fair deals in the market? Alternatively, is transparency only an issue of how much information is available or what kind of information should be available as well? We return to this issue after a brief discussion of the concept of transparency and its different types.

\section{Market transparency}

In general, market transparency is regarded as playing a central role in promoting the fairness and the efficiency of markets (Report, 2001). Market transparency can be defined as the ability of market participants to obtain information about the trading process, (e.g. price, order size, trading volume, risk, and trader identity) (Madhavan, 2000). There are several types of transparency, although most research on e-marketing focuses on transaction cost 
when explaining the underlying driving forces and the advantages of exploiting information technology (IT) (Hultman and Axelsson, 2007). Transparency is seen as a means of facilitating decreased transaction costs. For instance, the costs involved in identifying suitable products and/or suppliers and of undertaking comparisons between alternative propositions are reduced with greater transparency. The utilisation of IT has rejuvenated discussions on transparency as it offers consumers the ability to observe and share information which is generally not shared among partners in an exchange (Lamming et al., 2001).

Cost transparency, in industrial purchasing, is the sharing of information related to cost between suppliers and buyers. It often includes data that would otherwise be maintained secretly by both parties during negotiations (Lamming et al., 2001). Transparency has also been examined in other areas of businesses such as corporate communication (Christensen, 2002) and consumer marketing (Sinha, 2000). Furthermore, the concept of 'line of visibility' in services marketing - although not specifically addressing transparency - actually concerns transparency (Lovelock et al., 1999). However, in all cases, the key feature seems to be the capability to mutually share information that is not usually shared. Furthermore, relationship transparency, according to Eggert and Helm (2003), has been defined as any individual's perception of being notified about the suitable activities and characteristics of the other party involved in the interaction.

Hultman and Axelsson (2007) offered a classification of four types of transparency and three facets that are relevant to all types. The four types are: cost/price, technology, organisation, and supply. The three facets are: degree, direction and distribution of transparency. The degree of transparency refers to the extent to which information is shared between suppliers and buyers. Information may be fully, partially or even not shared at all (Lamming et al., 2001). Direction of transparency is concerned with the flow of information. Information flow in a buyer-seller relationship is typically bi-directional, but there are instances where the sharing of information is not reciprocal. This facet captures the non-reciprocal sharing of information between buyers and sellers. The third facet is concerned with the distribution of transparency. The unit of analysis for this facet changes from a dyad to that of a supply chain (Eggert and Helm, 2003). The distribution of transparency could either be direct or indirect. Specifically, direct transparency refers to transparency present in a specific relationship and indirect to transparency existing in a relationship that it is connected to a focal relationship.

Market transparency is a necessary condition for effective market functioning. From a consumer perspective, it strengthens their confidence as they can identify and choose products and services that offer the maximum value. This confidence, in turn, acts as an incentive to search for such offerings and stimulates competition. The greater the market transparency is (i.e. availability and relevance of information), the higher will be the consumers' confidence in the market. While transparency is a prerequisite for any free market, significantly different levels of transparency levels (i.e. information asymmetries) between buyers and sellers have harmful effects to its actors and the market economy.

\section{Price transparency}

The type of transparency this study focuses its attention on is cost/price transparency. Price transparency allows for comparisons of products and services available in the market, helps consumers determine the value of offerings and guides their choice of behaviour. Suppliers are often motivated to make comparisons tougher by masking price information in an attempt to manipulate consumer preferences (Carlin, 2009). Practices that obfuscate pricing involve the obvious concealment of prices in small print to inconspicuous ways of tossing in gifts or adding extra charges during the process of vending. The issue of price concealment is particularly acute for young and inexperienced consumers and products that are new and innovative. Such practices confound consumers and increase search costs required for 
decision-making (Ellison and Ellison, 2009; Ramsay, 2007). Commercial tactics involving less-transparent pricing information could consequently have a negative impact on both decision-making and on the purchase behaviour of consumers.

In addition to price obfuscation, limitations in consumers' cognitive abilities influence their buying decision-making. The capability of shaping preferences is limited and adversely affected when choices available increase and reach saturation (Bettman et al.,1998; Markman and Loewenstein, 2010; Schwartz, 2004). The use of mental short cuts (e.g. preferring reputed brands over cheaper alternatives, equating price with quality, following expert advice provided by the supplier) and contextual cues (e.g. availability of products) and influentials (e.g. attitudes and opinions of family and peers) are known coping strategies (Henry, 2005). However, with the increase in cognitive burden, consumers tend to neglect a lot of the information available to them (Bettman et al., 1998; Henry, 2005); instead undertaking strategies aimed at 'satisficing'. Satisficing is a blended word derived from 'satisfy' and 'suffice' referring to a strategy for decision-making that meets the criteria for adequacy rather than optimality in purchase behaviour (Prabha et al., 2007).

On account of the inherent complexities in psychological processes, as well as limits in cognitive abilities, conventional economic theory and choice models, according to van Boom (2011), often fail in the elucidation of consumer choice behaviour. Specifically, it has been argued that consumers do not always consider prices at their face value but in a broader perspective and ascribe greater meaning to them much above their monetary value (Liu and Soman, 2008). Specifically, they either underestimate or overestimate the significance of price in their decision-making processes. The undervaluing of price occurs when the context and personal attributes influence consumers to focus on features other than price. The overvaluing of price occurs when consumers consider price to signify quality even when price and quality of a product are completely uncorrelated (Chen et al., 2009; Hanf and von Wersebe, 1994; Kirchler et al., 2010). Regardless of how price information is used by consumers, availability of price information contributes to market transparency.

Although it is important to understand the coping strategies and price value adjustments in consumer choice behaviour, it is equally, if not more, important to understand why these phenomena occur. Logic dictates that if a decision has to be made in the absence of adequate and/or relevant information, alternative cues, short cuts and coping strategies are necessary. For instance, how could a consumer choose between two alternatives with no information on whether or not the prices are fair so that these two options represent fair deals? Given the knowledge that one is a fair deal and the other is not, the choice is straightforward. If both represent fair deals then the choice will be a matter of preference. When information for judging price fairness is missing, consumers will inevitably seek alternative cues for decision-making with the aim of minimising the risk of making a sub-optimal choice. Price information, though necessary, does not allow for judgements on price fairness; it only permits comparisons between competing alternatives without a reference standard.

From a consumer's perspective, judging whether the price of a product is fair could be possible by reference to its unit cost. That is, price fairness will reflect acceptable difference thresholds between the unit cost of a product/service and its selling price. Depending on the magnitude of that difference, consumers could decide if a product was offered at a fair price or not. Similar evaluations can be made for each alternative, prior to deciding what the best deal is. Although price fairness and best deal are not synonymous, the former is an important prerequisite of the latter in comparisons of alternative offerings that are priced differently. As early as 1776, Adam Smith made a distinction between natural price (i.e. the amount which is 'neither more nor less than what is sufficient to pay the rent of the land, the wages of labour, and the profits of the stock ... according to their natural rates) and market price (i.e. the price which may prevail at any given point in time, being regulated by the proportion 
between the quantity which is actually brought to market, and the demand of those who are willing to pay the natural price of the commodity).

In Adam Smith's years, it might have been easy to guess or estimate the natural price, but in our times, advancements in production technology and sophistication of management and marketing practices prevent the accuracy of such estimations. For instance, it is impossible for consumers to know the actual cost of a flat TFT 50"screen TV set, or the actual cost of an additional voice control added on a TV that usually causes a significant price increase in comparison to an identical set without this feature. The same applies to services. For example, what is the true cost of brain surgery, a flight, or a one-day training seminar? The same difficulty is likely to be encountered if a consumer wants to know the cost of each of the above in order to determine whether the price of a product or service is fair or not. To reiterate, price transparency allows for product/service comparisons but not for judgements pertaining to price fairness. Although a lack of cost transparency renders identification of best deals in the market impossible. We propose that its availability will largely eliminate this problem - an issue the discussion turns to next.

\section{Cost transparency}

Unit or product cost is 'the cost incurred by a company to produce, store and sell a unit of a particular product. Unit cost includes all fixed costs (i.e. plant and equipment) and all variable costs (labour, materials, etc.) involved in production' (Aspromourgos, 2007). Unit cost comprises all functions involved in the process of making and bringing a product to market and its estimation, according to Sharman and Vikas (2004), is a complex task. Another type of cost that can be accurately traced to a product or service with little effort is the direct cost. Direct cost is the cost of materials, labour and expenses related to the production of a product or the provision of a service. For instance, if a company makes jewellery, the direct cost of a ring will be made up of the cost of materials used in producing it and the labour cost involved. Similarly, the direct cost of a carpet cleaning service will be the workers' time (wages) to clean the carpet, and the cleaning materials used. Direct costs vary with the rate of output but are uniform for each unit of production. Direct costs are generally fixed in the short run and variable in the long run.

In addition to direct costs, companies incur indirect costs. Indirect costs can be related to manufacturing of a product (i.e. manufacturing overheads) and other costs (i.e. nonmanufacturing overheads). Manufacturing overheads cannot be easily traced to products and include, amongst others, indirect materials, indirect labour and other costs that are required for the production operations such as insurance, depreciation of machinery, and electricity. Non-manufacturing overheads are also indirect costs associated with expenses related to, amongst others, selling, administration and interest expenses (i.e. cost of borrowed money). Although non-manufacturing costs are not assigned to products, they are always considered as part of the total cost of providing a specific product to a specific customer. In other words, the selling price of any product must be greater than the sum of the product cost (direct material, direct labour, and manufacturing overheads) and the non-manufacturing costs and expenses for a company to be profitable.

Thus far, we have advocated that consumers do not have information to decide the price fairness of offerings. According to Xia et al. (2004), price fairness is a judgement of whether an outcome and/or the process to reach an outcome are reasonable, acceptable, or just and involves (from a cognitive point of view) a comparison of a price with a pertinent standard. At present, the pertinent reference standard is not available. The best consumers could do to arrive at some price fairness judgements is to attempt an educated guess of the direct unit cost of an offering, by looking at the prices of private labels. Usually, private labels offered at a lower price than branded products and a price comparison between private labels and national 
brands provides them with some idea regarding unit cost (Sinha, 2000). When there is no marked difference in the attributes of two products, whilst there is a noticeable difference in price, a comparison provides some idea of the likely unit cost of products based on which price fairness judgements can be based.

A lack of cost transparency means that consumers cannot accurately determine the direct unit cost of products (Bolton et al., 2003); consequently, they revert to other comparisons to determine price fairness (see Xia et al. (2004) for a review of price fairness perceptions). Comparing prices to references other than direct unit costs are likely to be biased, unjust and unwarranted. Such comparisons may lead to choosing offerings that are not fair deals while rejecting fairer options. Drawing from findings indicating that price transparency has led to a decrease in brand loyalty (Sinha, 2000), we argue that cost transparency and subsequent choice based on price fairness judgements will increase loyalty to products and services that offer high value. The fact that price comparisons erode brand loyalty is indicative of consumers' need for more informed choices. Nonetheless, there are ways for selling organisations to combat the effect of cost and price transparency; for instance, there will always be a demand for innovative new products, products of high quality or products that improve consumers' lives (Sinha, 2000). For such products, consumers will be willing to pay higher prices despite higher unit cost - price differentials.

The type of cost information that will be most useful to consumers for deciding price fairness is the direct unit cost or the direct unit cost including the manufacturing overheads. Availability of direct unit cost information will, undoubtedly, empower consumers. However, information on direct unit cost poses a problem especially for those consumers who do not actually know what direct unit cost is and what it includes. For example, if a consumer believes that an organisation incurs only manufacturing costs (excluding all indirect costs and expenses), they might become very critical of the gap between the direct unit cost and the price of a product, and judge the price of an offering as unfair. On the other hand, if a consumer knows that the direct unit cost excludes indirect costs (e.g. administration, storage and logistics, marketing), it is highly likely to accept a higher price as they will be aware of the additional costs involved in bringing a product to the market.

Cost transparency will influence consumers' tolerance to differences between direct unit cost and price of offerings. Larger differences between a product's direct unit cost and its price (i.e. difference thresholds) may be seen with scepticism and turn consumers away from such products. On the contrary, products with smaller differences between direct unit cost and price may be seen more favourably and considered as fair and good deals. Furthermore, comparisons between alternatives at the level of their direct unit costs will be possible. For example, a comparison of direct unit costs between two very similar products will indicate the level of production efficiency of the respective companies. This is an important comparison as it could inform consumers' choice behaviour beyond the level of personal gratification. That is, choosing products/services with the lower direct unit cost will be a vote of confidence for efficiently run companies.

\section{Benefits from the availability of cost transparency}

Increased market transparency facilitated by the Internet has helped in reducing information asymmetries between buyers and sellers (Grewal et al., 2003; Kung et al., 2002; Lindbeck and Wikstrom, 1999; Pitt et al., 2002; Reisch, 2003; Rha and Widdows, 2002). For example, facets of market functioning that have been positively impacted by greater transparency include information search behaviour by customers, corporate policy on information disclosure and third-party communication by consumer organisations. To reiterate, consumers can now retrieve, compare information and make effective decisions regarding products in a cost-effective and rapid manner. In addition, customers can share their personal 
experiences regarding products and services with a vast number of individuals (Stauss, 2000). Furthermore, product experiences which were previously available only after purchase (Klein, 1998) are now shared in reviews posted online by other users providing information to prospective buyers.

The proliferation of market information has increased consumers' market power (Lindbeck and Wikstrom, 1999). For instance, the ease of access to available information allows consumers to compare and evaluate various alternatives, minimising in that way their information search costs. In addition, price transparency allows customers to compare various options and employ savings maximisation strategies without compromising their satisfaction with the chosen options. In addition, information availability propels competition between firms. For example, companies compete well beyond a price to the point that the chain for some companies now begins with the consumer who initiates the process with a need and makes a request for the product, following which production begins (Van Raaij, 1998). In this instance, the roles coalesce, leading to a consumer becoming a prosumer or a comarketer. The Internet facilitates the assimilation of consumers in the value chain thereby modifying the boundaries between consumers and firms (Lindbeck and Wikstrom, 2003).

Availability of direct unit cost information will offer several advantages to consumers and companies. For consumers, the following two benefits are worth mentioning. First, it will allow consumers to make judgements on price fairness enhancing in that way their evaluation of alternatives. This will enhance consumers' buying decision-making as they will be able to use price fairness as a means of identifying best deals in the market and increasing satisfaction with their final choices. Second, it will help consumers extrapolate information pertaining to the efficiency level of companies which, in turn, may influence their choice of company. Consumers' decision to buy offerings from the most efficient companies will increase overall market efficiency. For companies, the provision of direct unit cost information will motivate them to use robust methods for estimating product/service costings (Kaplan, 1990) - a prerequisite for effective management and for building a sustainable competitive advantage - and prompt them to compete at the level that matters most; that is, efficient utilisation of resources in providing attractive offerings.

Given that direct unit cost information reflects the cost of materials and/or labour involved in producing a product, this could be used as an indication of quality. Currently, judgements on the quality of most offerings are based on price comparisons. Often, high prices are associated with high quality and vice versa. As this association does not always hold true, quality judgements in environments (i.e. markets) characterised by asymmetric information, disadvantages consumers and offers profitable opportunities to firms selling low quality goods at high prices to uninformed buyers (Cooper and Ross, 1984). Inadequately informed consumers in need of making judgements on the quality of products/services are severely disadvantaged and often subject to being misguided by 'dishonest' firms. Even if conditions of information equilibrium prevailed, prices and product attributes rarely convey adequate information for judgements on the quality of offerings. Consequently, consumer judgements are compromised as an additional search for other proxy indicators of quality (i.e. firm's reputation, warranties) and increased search costs (Cason and Friedman, 1999).

Consumer choice behaviour based on inadequate information often comes at a cost to their pockets (Cohen and Winn, 2007) and at a cost to the free market economy as information disequilibrium diminishes market efficiency (Kuhn and Martinez, 1996), distorts competition, and erodes the competitiveness of companies in the long term. Undoubtedly, availability of unit cost information will be a controversial issue. On the one hand, consumers may claim that this is one of the most basic and important rights that have long been overdue. That is, to be able to assess the price fairness of products and services they consider buying. Knowing that a price paid is a fair price will increase their satisfaction and confidence in the free 
market system. On the other hand, companies will most likely consider product costing to be an issue of 'internal affairs' and not a piece of information to become public knowledge. They could argue that price costings are reflected in prices and, as choices are vast in today's markets, consumers are free to choose products that meet both their needs and price expectations.

It has long been recognised that it is easy for companies to charge higher prices when information asymmetries exist in the market (Stiegler, 1966). The prevailing argument is that information asymmetry between buyers and sellers increases buyers' search costs (Biswas, 2004) and the lower the search costs for any actor in the market the lower will be the overall information asymmetry (Rothschild, 1974). For example, if all buyers were perfectly informed about the available price alternatives, 'perfect market conditions' would exist and any company, all else being equal, charging a higher price to its product than its competitors, will not be able to sell anything (Rothschild, 1974). Although, to a large extent, the relationship between search costs and information asymmetry holds true, we argue that price transparency even at 'perfect competition conditions' does not provide consumers information that is needed for price fairness judgements. In order to eradicate information asymmetries, consumers should know if an assigned price is a fair price - this can only be possible when information on direct unit cost of offerings, allowing for price-cost difference to be estimated, becomes available.

\section{Consumer empowerment and market efficiency}

Cost transparency will increase consumer empowerment. Consumer empowerment is defined as the subjective state that is evoked by perceptions of greater personal control (Skinner, 1996; Wathieu et al. 2002) and it occurs through the provision of greater information or enhanced consumer understanding (Brennan and Ritters, 2004; Cutler and Nye, 2000; Rust and Oliver, 1994). Therefore, consumer empowerment results from a 'gains' comparison in terms of previously allowed control to that which exists at present. Use of power is capable of producing desirable outcomes and prevents undesirable outcomes from occurring. However, it is the increased perception of greater control that evokes empowerment; hence, it might be experienced whether there is an increase in actual control or not (Wathieu and Bertini, 2007). Empowered consumers exert control over the elements of the marketing mix, such as price (Wathieu et al., 2002) and certain characteristics of the communication process (Cova and Pace, 2006; Firat and Dholakia, 2006).

The greater personal control exercised by empowered consumers (Denegri-Knott et al., 2006) can be exerted in three ways. First, consumers feel a sense of empowerment when they combine their skills and resources in order to force producers to undertake those actions, which they otherwise would not perform. Secondly, consumers obtain power when they are able to influence and even create special spaces in the market in which they build their own cultural identity. Thirdly, consumers are empowered when they are capable of counteracting the communication of firms and institutions thereby affecting their credibility (Hunter and Garnefeld, 2008). Therefore, the extent of consumer empowerment depends on the number and quality of value propositions, which exist in the market, market knowledge, and ability to gather new market information and take advantage of alternative value propositions. Cost transparency will enhance consumer empowerment through better evaluation of alternative value propositions and increased levels of market knowledge.

Empowered consumers need not be essentially decisive. Consumers make every effort to derive the greatest satisfaction from the consumption process, and the better firms facilitate the process of consumer empowerment, the better their sense of contentment is (Wright et al., 2006). In a stark contrast to the above view, consumer empowerment is considered as a process through which consumers gradually become more self-governing subjects (Shankar 
et al., 2006) who are accountable for the alternatives that affect their purchase decisions and consumption activities. Cost transparency empowers consumers by providing information that allows them to estimate cost-price differences and determine price fairness. For example, a comparison between competing alternatives (other factors remaining the same) suggests that a firm with the lowest price and the lowest unit cost product offers the best deal and makes a better use of its resources, respectively. On account of judicious utilisation of resources, it is likely that such firms are also more socially responsible. The support of such efficient firms by consumers would imply putting pressure on the other firms to enhance their efficiency in terms of resource utilisation. Thus, consumer choice behaviour would promote operational efficiency of companies.

Efficiency levels attained, through leveraging resources that contribute most to their success, differs amongst companies, yet regardless; all products/services produced or provided by companies reach the market and compete with other offerings. That means, less efficient companies have the opportunity to compensate for their inefficiencies through careful pricing and positioning of their offerings. By the same token, consumers do have the freedom to choose the alternative that offers the maximum value but without knowing (a) whether or not prices are fair and (b) how to safeguard their short and long term interests through an increase of the value of all offerings in the marketplace. Consequently, their buying decision-making is compromised as evaluations of alternative offerings lack an objective reference standard (i.e. direct unit cost) for comparison, and choice is not informed by the operational efficiency of providers. Thus, an inadequately informed choice could be, and often is, sub-optimal for consumers, most companies and the economic system.

The notion that consumer empowerment contributes to market efficiency requires empowerment to shift its focus away from 'more information' to that of 'pertinent information'. Pertinent information needed by consumers should not be seen as a gain that comes as someone else's loss (i.e. supply side). More information about offerings to choose from does not help consumers or producers and certainly has a negative impact on market efficiency. For example, consider a range of almost identical competing products that are priced similarly, though the unit cost of each product varies considerably. If consumers were to choose the product with the lower unit cost, their money would have been directed to the most efficient company. The most efficient company will gain both from higher sales and perhaps higher profit margins. Unless other companies can innovate and differentiate their products/services, they will be at a competitive disadvantage. That is, highly priced products with higher unit costs may not fare well in the market unless the higher unit cost reflects a noticeable difference in the quality of those products.

Competition driven by cost transparency will eventually leave in the market only the efficiently run companies - at which point price-based competitive advantages will be a sensible strategy for companies with lower non-manufacturing costs. For instance, if a company has significantly lower non-manufacturing costs than others, it will have the flexibility to lower the price of its products while maintaining reasonable profit margins. The low cost - low price strategy would be the main strategy for gaining a competitive advantage. Competitors with higher non-manufacturing costs will not have this advantage, and unless they improve (i.e. lower their non-manufacturing costs), they will need to squeeze their profit margins in order to remain competitive, or else go out of business. When the market reaches this point, consumers will be able to decide price fairness and reach informed decisions on best deals. By comparing costs and prices, consumers will know what competing options offer the best value for money. With the exception of 'new to market' innovative products and services, and until competitors move into the market with similar products, all other offerings will be open to such evaluations. 
For businesses, the main objectives are to maximise its profits and to protect the conditions that supports their existence and growth. For consumers, the main objectives should be to maximise the value they get from market exchanges and safeguard the conditions for value maximisation. Companies are fully aware of what needs to be done in order to achieve their objectives. Consumers are not, and until they find ways of obtaining the maximum of value in market exchanges and support market efficiency with their choices, they will be at peril of having to choose the best alternative out of a pool of sub-optimal ones.

\section{Discussion}

The theme of this article has focused on the demand side of a free market economy and the critical question has been 'do consumers in pursuit of self-interest fulfilment have adequate information to achieve utility maximisation?' Largely owing to the Internet, prices have become more transparent and the availability of price information has contributed to better buying decision-making (Biswas, 2004). However, although price transparency helps identify the best deal amongst a set of considered alternatives, it does not provide information pertaining to whether or not alternatives are a fair deal. Hence, the question: Is the best deal necessarily a fair deal? A fair deal is difficult to define but consumers are increasingly seeking to know whether prices advertised reflect a fair transaction.

To most consumers, fair means the seller's actual costs plus a reasonable premium. To the degree that buyers can determine what a fair price is, they can seek the best bargain available to avoid overpaying for brands whose prices are clearly out of line (Sinha, 2000). Cost transparency should therefore enable consumers to make price fairness judgements.

We have argued that availability of unit cost information will be beneficial both to consumers and companies. However, would it be uniformly beneficial to all actors in the marketplace? Consumers on the one hand will certainly gain from cost transparency (i.e. better decisionmaking), with the worst-case scenario being to misuse or ignore this information. Companies, on the other hand, could find that the provision of unit cost information impairs their ability to obtain higher profit margins, turn products and services into commodities, reduce customer loyalty to their brands and affect their reputation by targeting market perceptions of price unfairness (Sinha, 2000). Notwithstanding the benefits accruing from cost transparency for the supply side (i.e. prompt companies to make better and more efficient utilisation of resources), the drawbacks are disproportionate when compared to those for the demand side. Should companies, therefore, refuse to make unit cost information available if and when the demand side requests it? Or, and from a marketing point of view, should companies aim to satisfy customers' needs even when it comes to cost transparency?

Price fairness judgement involves a comparison of a price with an appropriate standard, reference, or 'norm' (in this case unit cost). Such comparisons are fairly straightforward to be made, although how price fairness and/or price unfairness judgements can be made and articulated is difficult to predict and is an area in need of further research. A price comparison leading consumers to judgements of equality, advantaged inequality, or disadvantaged inequality will be replaced with judgements pertaining to what alternative is fairest. With unit cost availability, comparisons will be made between the price of an offering and its unit cost rather than against the prices of other offerings. Nonetheless, price fairness perceptions differ for different customers, products and services, company types and cultures. Consequently, perceptions of price fairness are expected to vary widely and to be biased by the self-interests of the individual. Despite such differences, cost transparency will allow consumers to buy the fairest and best option leading to satisfaction maximisation and backing efficient companies. An important issue is who should initiate and regulate cost transparency? Should it be enforced by consumers, firms, and/or governments? It is reasonable to assume that consumers should exercise their rights and demand that companies provide unit cost information of their 
products and services. It is moreover common knowledge that many consumers participate in online blogs and often voice their opinions in online forums. This could be taken one step further, with consumers sharing their views of the need for cost transparency, with other consumers. Social networking, with consumers having greater control over it, can easily facilitate the sharing of such views. Ultimately, the decision pertaining to the provision of unit cost information rests with organisations. Companies can make this information available only at their will and it is difficult to predict their responses. However, consumers have nothing to lose and much to gain from cost transparency. The role of government is not needed beyond the level of overseeing the adherence of companies to the laws and regulations or reporting accurate information.

\section{Conclusion}

Cost transparency is not a new idea, but considering it from a consumers' perspective, it has the potential of turning into a massive scale initiative. However, regardless of the extent of its appeal, it should always be the responsibility of consumers to make it happen. The rationale is that optimal decision-making is based on available information. In addition to the amount of available information, we stress the need for 'pertinent information' as well. Cost transparency, on the one hand, will result in more effective decision-making and choice behaviour where the customers' needs will be fully met and satisfaction will reach its maxim. On the other hand, companies will have to differentiate their offerings from those of competitors, by maximising efficiency levels while searching for profitable innovations. Although market economies are enormously complicated, there are disturbing power imbalances and information asymmetries in favour of the supply side. The demand side (i.e. consumers) has yet to play its role of safeguarding its interests and making a decisive contribution in a self-regulated market. This article paves the way in addressing this very issue by offering one possible way forward.

\section{References}

Ancarani, F. (2002), "Pricing and the Internet: Frictionless commerce or pricer's paradise?", European Management Journal, Vol. 20, No. 6, pp. 680-687.

Aspromourgos, T. (2007), "Adam Smith's Treatment of Market Prices and their Relation to Supply and Demand" (Accessed July 20, 2014), [available at http://conference.net.gr/HET/pdf/7thconference/Aspromourgos_fulltext.pdf].

Baye, M.R. and Morgan, J. (2002), "Information gatekeepers and price discrimination on the internet”, Economics Letters, Vol. 76, No. 1, pp. 47-51.

Bettman, J.R., Luce, M.F. and Payne, J.W. (1998), "Constructive consumer choice processes", Journal of Consumer Research, Vol. 25, No. 3, pp. 187-217.

Biswas, D. (2004), "Economics of information in the web economy: Towards a new theory?" Journal of Business Research, Vol. 57, No. 7, pp. 724-733.

Bolton, L.E. Warlop, L. and Alba, J.W. (2003), "Consumer Perceptions of Price (Un) Fairness," Journal of Consumer Research, Vol. 29, No. 4, pp. 474-491.

Brennan, C. and Ritters, K. (2004), "Consumer Education in the UK: New Developments in Policy, Strategy, and Implementation," International Journal of Consumer Studies, Vol. 28, No. 2, pp. 97-107.

Carlin, B.I. (2009), "Strategic price complexity in retail financial markets", Journal of Financial Economics, Vol. 91, No. 3, pp. 278-287.

Carton, S. (2000), "Consumer power drives today's e-economy", Click Z, 21 June, (Accessed Nov 29, 2014), [available at http://www.clickz.com/tech/lead_edge/article.php/ $825561]$. 
Cason, T. and Friedman, D. (1999), "Customer search and market power: Some laboratory evidence", Advances in Applied Microeconomics, Vol. 8, pp. 71-99.

Chen, T., Kalra, A., and Sun, B. (2009), "Why do consumers buy extended service contracts?", Journal of Consumer Research, Vol. 36, No. 4, pp. 611-623.

Christensen, L.T. (2002), "Corporate communication: The challenge of transparency", Corporate Communications, Vol. 7, No. 3, pp. 162-168.

Cohen, B., Winn, M.I. (2007), "Market imperfections, opportunity and sustainable entrepreneurship", Journal of Business Venturing, Vol. 22, No. 1, pp. 29-49.

Cooper, R. and Ross, T.W. (1984), "Price Qualities and Asymmetric Information: The Competitive Case", The Review of Economic Studies, Vol. 51, No. 2, pp. 197-207.

Cova, B. and Pace, S. (2006), "Brand Community of Convenience Products: New Forms of Customer Empowerment - the case "my Nutella the Community"", European Journal of Marketing, Vol. 40, No. 9/10, pp. 1087-1105.

Cova, B. and Dalli, D. (2009), "Working consumers: The next step in marketing theory?", Marketing Theory, Vol. 9, No. 3, pp. 315-339.

Cutler, T.J. and Nye, A.D. (2000), “Anything but 'empowerment'? Smokers, tar and nicotine data and cigarette design", Health, Risk, and Society, Vol. 2, No. 1, pp. 69-81.

Denegri-Knott, J., Zwick, D. and Schroeder, J.E. (2006), "Mapping Consumer Power: An Integrative Framework for Marketing and Consumer Research", European Journal of Marketing, Vol. 40, No. (9-10), pp. 950-971.

Eggert, A. and Helm, S. (2003), "Exploring the impact of relationship transparency on business relationships: A cross-sectional study among purchasing managers in Germany", Industrial Marketing Management, Vol. 32, No. 2, pp. 101-108.

Ellison, G. and Ellison, S.F. (2009), "Search, obfuscation, and price elasticities on the internet", Econometrica, Vol. 77, No. 2, pp. 427-452.

Evans, P. and Wurster, T.S. (2000), Blown to bits: How the new economics of information transforms strategy, Boston: HBS Press.

Firat, A.F. and Dholakia, N. (2006), "Theoretical and Philosophical Implications of Postmodern Debates: Some Challenges to Modern Marketing”, Marketing Theory, Vol. 6, No. 2, pp. 123-162.

Grewal, D., Iyer, G.R., Krishnan, R. and Sharma, A. (2003), "The Internet and the pricevalue- loyalty chain", Journal of Business Research, Vol. 56, No. 5, pp. 391-398.

Hanf, C.H. and von Wersebe, B. (1994), "Price, quality, and consumers' behaviour", Journal of Consumer Policy, Vol. 17, No. 3, pp. 335-348.

Hansen, U., Rezabakhsh, B. and Bornemann, D. (2006), Market transparency via the Internet - A new challenge for consumer policy. In: K.G. Grunert and J. Thogersen (Eds.), Consumers, policy and the environment, pp. 233-249. New York: Springer.

Henry, P. (2005), Is the internet empowering consumers to make better decisions, or strengthening marketers' potential to persuade? In C. P. Haugtvedt, K.A. Machleit, \& R.F. Yalch (Eds.), Online consumer psychology: Understanding and influencing consumer behavior in the virtual world (pp. 345-360). New Jersey: LEA.

Hoffman, D.L. and Novak, T.P. (1997), "A new marketing paradigm for electronic commerce", The Information Society, Vol. 13, No. 1, pp. 43-54.

Hultman, J. and Axelsson, B. (2007), "Towards a typology of transparency for marketing management research", Industrial Marketing Management, Vol. 36, No. 5, pp. 627635.

Hunter, G.L. and Garnefeld, I. (2008), "When does Consumer Empowerment Lead to Satisfied Customers? Some Mediating and Moderating Effects of the EmpowermentSatisfaction Link", Journal of Research for Consumers, Vol. 15, No. 1, pp. 1-14. 
Kaplan, R.S. (1990), "Limitations of cost accounting in advanced manufacturing environments", Measures for Manufacturing Excellence, pp. 15-38.

Kirchler, E., Fischer, F. and Hölzl, E. (2010), "Price and its relation to objective and subjective product quality: Evidence from the Austrian market", Journal of Consumer Policy, Vol. 33, No. 3, pp. 275-286.

Klein, L.R. (1998), "Evaluating the potential of interactive media through a new lens: Search versus experience goods", Journal of Business Research, Vol. 41, No. 3, pp. 195-203.

Kuhn, K-U. and Martınez, C.B. (1996), "Market transparency, competitive pressure, and price volatility", London: Centre for Economic Policy Research. Discussion Paper No. 1472.

Kung, M., Monroe, K.B. and Cox, J.L. (2002), "Pricing on the Internet", Journal of Product \& Brand Management, Vol. 11, No. 5, pp. 274-288.

Lamming, R.C., Caldwell, N.D., Harrison, D.A. and Phillips, W. (2001), "Transparency in supply relationships: Concept and practice", Journal of Supply Chain Management, Vol. 37, No. 4, pp. 4-10.

Lindbeck, A. and Wikstrom, S. (1999), "ICT and household-firm relations". Stockholm: University of Stockholm, Institute for International Economic Studies, Seminar Paper No. 677.

Lindbeck, A. and Wikstrom, S. (2003), "E-exchange and the boundary between households and organizations", Kyklos, Vol. 56, No. 3, pp. 315-340.

Liu, M.W. and Soman, D. (2008), Behavioral pricing, In C. P. Haugtvedt, P.M. Herr, and F.R. Kardes (Eds.), Handbook of Consumer Psychology (pp. 659-681). New York: Psychology Press.

Lovelock, C.H., Lewis, B. and Vandermerve, S. (1999), Services marketing: European perspectives, London: Prentice-Hall.

Madhavan, A. (2000), "Market microstructure: A survey", Journal of Financial Markets, Vol. 3, No. 3, pp. 205-258.

Markman, A.B. and Loewenstein, J. (2010), "Structural comparison and consumer choice", Journal of Consumer Psychology, Vol. 20, No. 2, pp. 126-137.

Murphy, T. (2000), Web rules: How the Internet is changing the way consumers make choices, Chicago: Dearborn.

Pitt, L.F., Berthon, P., Watson, R.T. and Zinkhan, G.M. (2002), "The Internet and the birth of real consumer power", Business Horizons, Vol. 45, No. 4, pp. 7-14.

Prabha, C., Connaway, L.S., Olszewski, L. and Jenkins, L.R. (2007), "What is enough? Satisficing information needs", Journal of Documentation, Vol. 63, No. 1, pp. 74-89.

Ramsay, I. (2007), Consumer law and policy: Text and materials on regulating consumer markets (2nd ed.), Oxford; Portland, Or: Hart.

Redmond, W.H. (2000), "Consumer rationality and consumer sovereignty", Review of Social Economy, Vol. 58, No. 2, pp. 177-196.

Reisch, L.A. (2003), "Potentials, pitfalls, and policy implications of electronic consumption", Information \& Communication Technology Law, Vol. 12, No. 2, pp. 93-109.

Report (2001), "Transparency and Market Fragmentation," Report from the Technical Committee of the International Organization of Securities Commissions.

Rezabakhsh, B., Bornemann, D., Hansen, U. and Ulf Schrader, U. (2006), "Consumer Power: A Comparison of the old economy and the Internet economy", Journal of Consumer Policy, Vol. 29, No. 1, pp. 3-36.

Rha, J-Y. and Widdows, R. (2002), "The Internet and the consumer: Countervailing power revisited", Prometheus, Vol. 20, No. 2, pp. 107-118.

Rha, J-Y., Widdows, R., Hooker, N.H. and Montalto, C.P. (2002), "E-consumerism as a tool for empowerment", Journal of Consumer Education, Vol. 19, No. 20, pp. 61-69. 
Rothschild, M. (1974), "Searching for the lowest price when the distribution of prices is unknown", Journal of Political Economy, Vol. 82, No. 4, pp. 689-711.

Rust, R.T. and Oliver, W.R. (1994), "Video Dial Tone: The New World of Services Marketing", Journal of Services Marketing, Vol. 8, No. 3, pp. 5-16.

Schwartz, B. (2004), The paradox of choice: Why more is less (1st ed.), New York: Ecco.

Shankar, A., Cherrier, H. and Canniford, R. (2006), "Consumer Empowerment: A Foucauldian Interpretation", European Journal of Marketing, Vol. 40, No. 9/10, pp. 1013-1030.

Sharman, P.A. and Vikas, K. (2004), "Lessons from German Cost Accounting", Strategic Finance, Vol. 86, No. 6, pp. 28-35.

Shipman, A. (2001), "Privatized production, socialized consumption? Old producer power behind the new consumer sovereignty", Review of Social Economy, Vol. 59, No. 3, pp. 331-352.

Sinha, I. (2000), "Cost transparency: The net's real threat to prices and brands", Harvard Business Review, Vol. 78, No. 2, pp. 43-50.

Skinner, E.A. (1996), "A Guide to Constructs of Control”, Journal of Personality and Social Psychology, Vol. 71, No. 3, pp. 549-570.

Smith, A. (1776), Wealth of Nations, Oxford University Press, Oxford, U.K.

Stauss, B. (2000), Using new media for customer interaction: A challenge for relationship marketing. In: T. Hennig-Thurau \& U. Hansen (Eds.), Relationship marketing: Competitive advantage through customer satisfaction and customer retention, (pp. 233-254). Berlin: Springer.

Stiegler, G.J. (1966), The theory of price, New York: Macmillan \& Co.

Urban, G.L. (2002), Consumer power and the Internet, Cambridge, MA: Massachusetts Institute of Technology, Sloan School of Management, Project Report.

Van Raaij, W.F. (1998), "Interactive communication: Consumer power and initiative", Journal of Marketing Communications, Vol. 4, No. 1, pp. 1-8.

Van Boom, W.H. (2011), "Price Intransparency, Consumer Decision Making and European Consumer Law”, Journal of Consumer Policy, Vol. 34, No. 3, pp. 359-376.

Wathieu, L. and Bertini, M. (2007), "Price as a stimulus to think: The case for wilful overpricing", Marketing Science, Vol. 26, No. 1, pp. 118-129.

Wathieu, L., Brenner, L., Carmon, Z., Chattopahyay, A., Wetenbroch, K., Drolet, A., Gourville, J., Muthukrishnan, A.V., Novemsky, N., Ratner, R.K. and Wu, G. (2002), "Consumer Control and Empowerment: A Primer", Marketing Letters, Vol. 13, No. 3, pp. 297-305.

World Bank Group, (2014), Household consumption expenditure indicators, Data, (Accessed Dec 29, 2014), [available at http//: data.worldbank.org/ indicator/ NE.CON.PETC.ZS].

Wright, L.T., Newman, A. and Dennis, C. (2006), "Enhancing Consumer Empowerment", European Journal of Marketing, Vol. 40, No. 9/10, pp. 925-935.

Xia, L., Kent, B.M. and Jennifer, L.C. (2004), "The Price Is Unfair! A Conceptual Framework of Price Fairness Perceptions", Journal of Marketing, Vol. 68, No. 4, pp. 115. 